\title{
MULTICULTURALIDAD ECUATORIANA E HISTORIA NACIONAL
}

\section{ECUADORIAN MULTICULTURALISM AND NATIONAL HISTORY}

\author{
Manuel Ferrer Muñoz \\ Instituto de Altos Estudios Nacionales, Quito. Ecuador/Ecuador \\ ferrermuma@gmail.com
}

Recibido/Received: 11/08/2014

Modificado/Modified: 20/08/2014

Aceptado/Accepted: 30/09/2014

\section{RESUMEN}

Este estudio, que forma parte de una investigación más amplia sobre la historiografía ecuatoriana, analiza el papel ejercido por la institución estatal en el Ecuador como orientadora de las tareas que contribuyen a configurar las líneas directrices de una identidad nacional a partir de una visión histórica que le sirva de fundamento. Para ello resulta clave el diseño de imaginarios que sirvan para explicar la idiosincrasia nacional, entre los cuales desempeñan un papel esencial los de 'lo español' y 'lo indígena'. En la concreción de esas aspiraciones adquieren una gran importancia la escuela, los libros de texto y los museos, como instrumentos para la difusión de una historia 'nacional' que, por fuerza, debe hacerse eco de la conformación multicultural del Ecuador.

\section{PALABRAS CLAVE}

Nacionalismo, Estado-Nación, imaginario nacional, política educativa, escuela, libros de texto.

\section{SUMARIO}

1. Competencias educativas del Estado. 2. El papel del Estado en la conformación del nacionalismo ecuatoriano. 3. Las políticas educativas, la escuela y la enseñanza de la historia 'nacional'. 4. El reconocimiento de la multiculturalidad, punto de arranque en el aprendizaje de la historia 'nacional'. 5. Conclusiones. Bibliografia

\begin{abstract}
This study, part of a broader research on Ecuadorian historiography, details the role of the state institution in Ecuador as a guide for the tasks contributing to shape the guidelines of a national identity on the grounds of a historical view. Designing imaginaries useful to explain the national character (idiosyncrasies) is crucial to achieve it. Among the outstanding imaginaries are "what is Spanish" and "what is Aboriginal". Educational institutions, text books and museums become of great importance as a means to spread a 'national' History that must have an effect in the multicultural conformation of Ecuador, getting to the concretion of those wishes.
\end{abstract}

\section{KEYWORDS}

Nationalism, Nation State, collective imagination, education policy, school, textbooks.

\section{CONTENTS}

1. State Educational Responsibilities. 2. State role in the Ecuadorian Nationalism configuration. 3. Education policies, Educational institutions, and 'National' History pedagogy. 4. Multiculturality acknowledgment as the starting point for the 'National' History learning. 5. Conclusions. References. 


\section{COMPETENCIAS EDUCATIVAS DEL ESTADO}

En la modulación de las representaciones sociales de los habitantes de los territorios colonizados por España y Portugal en torno a la herencia colonial, el sustrato indígena y el aporte de sangre africana durante la centuria decimonónica, operan diversos factores que han de ser analizados en profundidad, si se quiere desentrañar la problematicidad de esos imaginarios, encorsetados muchas veces por las tendencias a la idealización, al estigma o a la simplificación en nombre de unos planteamientos esencialistas, que desconocen, además, el hecho de que, como ha explicado con acierto Luis Carlos Castillo en continuidad con Benedict Anderson, la nación constituye un artefacto cultural que ha sido inventado y producido con el desarrollo de la modernidad, sin que esa condición de 'inventado' o 'imaginado' se equiparare a una ilusión que la prive de realidad tangible (Castillo Gómez, 2009:19).

Resulta, pues, obligado el rechazo de aquellos estereotipos que, en sus explicaciones de las identidades, canonizan caracteres invariables y sustantivos, y olvidan que toda cultura conlleva siempre unos elementos de toxicidad que sólo se depuran mediante el diálogo y la comunicación con el otro.

Se sigue de ahí la importancia de conocer las visiones de los historiadores, de los literatos y de la prensa ecuatoriana del siglo XIX, que procuran un referente imprescindible para explicar el proceso de elaboración de aquellos imaginarios durante las décadas que siguieron a la independencia nacional. Esas aportaciones deben ser complementadas por el análisis de los programas de educación y los planes de enseñanza, los libros de texto, o los museos como instrumentos generadores de una idiosincrasia nacional, en cuanto recipientes de objetos 'nacionales' y representaciones de pueblos y de tiempos pasados (Radcliffe y Westwood, 1999:118). Anderson sostiene a este propósito que "los museos y la imaginación museística son profundamente políticos" (1993:249). Y ésa es, en efecto, la perspectiva de acercamiento de Octavio Paz a la visión que el Museo Nacional de Antropología de la Ciudad de México proyecta del pasado nacional mexicano (2007:412-415).

En efecto, para satisfacer los anhelos identitarios de los integrantes del Estado-Nación, la organización estatal que se sustenta en cada realidad nacional -o plurinacional- se sirve de herramientas como la enseñanza, los museos o los medios de comunicación, a través de las cuales acuña, difunde categorías sociales de referencia que pueden no ser inocentes, y alienta las historias oficiales como un modo de producción y de control del pasado (Torres Carrillo, 2003:198-199, y Radcliffe y Westwood, 1999:32 y 125), asumiendo competencias que, aunque no le pertenecen en exclusiva, considera redituables en alto grado. Contra esa pretensión había advertido Belisario Quevedo: "sería ridículo, absurdo, pretender que los gobiernos dejando de gobernar, se pongan a dar a las multitudes lecciones técnicamente pedagógicas para formar el espíritu nacional" (1981:299). Se precisa, en todo caso, que la puesta en marcha de esos instrumentos vaya precedida de investigación y estudio que conjuren el riesgo de las improvisaciones atolondradas.

No resulta, pues, extraño que, en países como el Ecuador, el himno nacional aparezca impreso en la mayoría de los textos escolares, con el evidente objetivo de infundir espíritu republicano y patriótico, y de inculcar en la mente de los jóvenes estudiantes unos cuantos imaginarios claves en la identidad de una nación donde ahora reinan el gozo y la paz, y que se muestra orgullosa de los hijos que supieron derramar su sangre para liberar a la patria del yugo ibérico (Radcliffe y Westwood, 1999:98): porque de esa conjunción de republicanismo y patriotismo deriva "una visión trágica de la nación cuya existencia sería impensable sin el concurso de la sangre derramada" (Uribe, 2005:226-227). La misma extensión que algunos 
manuales escolares destinados a la enseñanza de la historia dedican a pormenorizar los avatares del himno corrobora la importancia grande que se concede a ese símbolo patrio: sería el caso de Holguín Arias (1994:281-288).

Y, si atendemos a la vecina Colombia, apreciaremos que, en su historiografía y en la enseñanza de su historia nacional, se apela a la invocación de héroes, al orgullo como nación $\mathrm{y}$ al patriotismo como recursos para tratar de resolver las crisis de identidad y de legitimidad que se agudizaron durante la cuarta década del siglo XX, al tiempo que se aplica un proceso de 'tradición selectiva', que privilegia algunos aspectos de la historia y de la cultura, mientras margina otros (König, 1994:39-40 y Castillo Gómez, 2009:79). Así lo postuló Raimundo Rivas, integrante de la llamada Generación del Centenario, quien, para dar solución a esos problemas, recomendó reavivar en el alma nacional una relación intensa con la historia patria y sus mediadores (en especial, los héroes de la independencia) (Castillo Gómez, 2009:41, nota 46).

Pocos pensadores -y ningún político- del siglo XIX han acertado a expresar con la hondura de Domingo F. Sarmiento la importancia de la educación como sustento de las nuevas repúblicas que surgieron en América entre la segunda y la tercera década de la centuria. En Argirópolis, publicada en 1850 sin el nombre del autor, Sarmiento resumió el proyecto de una 'república moderna' en América del Sur, en la que la educación constituía uno de los pilares esenciales, y donde se traza un recorrido de la experiencia política de un buen tramo de la historia de Argentina que brilla con luz propia, porque interpreta ese pasado a la luz de los hechos y no de las teorías.

Desafortunadamente, los anhelos de Sarmiento distarían de verse cumplidos, por lo que estamos seguros de que no calumniamos a ningún país del subcontinente si aplicamos a sus establecimientos docentes del siglo XIX aquella malintencionada y aguda frase atribuida con más o menos fundamento a Bernard Shaw: "mi educación se vio interrumpida por mi ingreso a la escuela" (cit. en Ospina, 1997:123).

La implicación del Estado en la política educativa, a través de su contribución a la forja de una historia nacional, no obsta para que, en el diseño de la política pública, resulte imprescindible el concurso de la población a que va dirigida, en la condición de actores y no de meros espectadores pasivos, testigos cuanto más de lo que para ellos promueven las clases 'pensantes'. Sin esa voluntad política de comprometer a la ciudadanía en las políticas del Estado, cualquier proyecto educativo de largo plazo nace condenado al fracaso.

\section{EL PAPEL DEL ESTADO EN LA CONFORMACIÓN DEL NACIONALISMO ECUATORIANO}

Como advirtió Ernest Gellner (2001:71), el nacionalismo no es el despertar de unidades míticas, supuestamente naturales; sino que resulta de la cristalización de nuevas unidades, gracias a las condiciones imperantes en un momento determinado, si bien utilizando como materia prima herencias culturales e históricas del mundo prenacionalista. En continuidad con esos planteamientos, Enrique Ayala sostiene que la aparición de las comunidades políticas modernas a las que llamamos Estados precede a la construcción de las modernas naciones; y que toda nación reclama una base estatal concreta y un esfuerzo consciente por crearla y desarrollarla desde el poder estatal (2002:75-76).

El caso del Ecuador parece abonar esa interpretación, pues, a la vista de las inconsistencias observables en su conformación histórica, podría concluirse, de acuerdo con 
las tesis de Juan Maiguashca y de Pablo Ospina, que el nacionalismo posee más bien origen estatal a través de la penetración de su burocracia en las regiones, y mediante la actuación en torno a tres ejes -la religión católica, el mestizaje y la cuestión de límites- y el empleo de tres instrumentos: las vías de comunicación, el ejército y la escuela, que permiten la transición del egoísmo individual a la valoración del grupo como acto de solidaridad y de exclusión respecto a los de fuera (Ospina Peralta, 1996:114 y 117, y Todorov, 2011:204-205).

Tal vez haya mucho de carga ilusoria en la esperanza depositada en esos mecanismos como medios para la superación de los intereses personales. Si atendemos a las duras afirmaciones de William Ospina acerca de las realidades de Colombia, cuesta trabajo superar el desánimo: "cualquier colombiano lo sabe: aquí nada sirve a un propósito público. Aquí sólo existen intereses particulares. El colombiano sólo concibe las relaciones personales, sólo concibe su reducido interés personal o familiar; y a ese único fin subordina toda su actividad pública y privada". Palabras como 'patria' causan risa en Colombia” (1997:15).

Jorge Núñez, por su parte, también ha subrayado el papel del Estado como elemento articulador de todos los demás que conforman la imagen nacional del Ecuador, por cuanto "utiliza su autoridad y poder para actuar sobre la historia y la historiografia" (2003:208).

Respecto a la escuela hay que subrayar la importancia que adquirió la instrucción pública a partir de 1830 como vehículo para la enseñanza de los orígenes nacionales desde la perspectiva de la fusión de dos mundos, el indígena y el español (Ospina Peralta, 1996:118). Tal vez fuera Vicente Rocafuerte quien entendió con más perspicacia la importancia de la educación al servicio de la formación del espíritu nacional, que requería cultivar la inteligencia del pueblo e instruirlo en el cumplimiento de sus deberes. No obstante, la concreción práctica de su empeño, inspirado en el modelo de la escuela lancasteriana y en la apertura de escuelas para niñas, distó de resultar satisfactoria (Paladines Escudero, 2009:145147).

Se advierte en Rocafuerte una contraposición entre sus ideales de intelectual y de político comprometido con los principios del liberalismo político y su gestión como presidente de la República que, si bien busca la plasmación de un programa innovador, aparece también marcada por un estilo de gobierno no precisamente respetuoso con las opiniones discrepantes. Esta doble vertiente de la personalidad de Rocafuerte aparece recogida con acierto en uno de los textos escolares de Educación Básica de la Editorial Don Bosco, aparecido en 2000, que presenta simultáneamente a Rocafuerte como un "paréntesis civilizador en medio del floreanismo" y como gobernante despótico (Estudios Sociales 10 E. B., 2000:10-11).

En el ambiente de grandes expectativas que acompañó a los primeros pasos de la revolución marcista, que depuso al general Juan José Flores, no faltaron algunos gestos que pretendían convertir en realidad el reconocimiento del derecho a la instrucción pública que asistía a todas las clases del Estado. Por eso, y con el referente de las becas en colegios que Bolívar había concedido en favor de los indígenas, se establecieron trece becas, dotadas de los fondos de los colegios, destinadas a otros tantos indígenas: dos en el seminario de San Luis, en Quito; dos en el convictorio de San Fernando, también en Quito; dos en el colegio de San Diego de Ibarra; dos en el de San Vicente, en Latacunga; una en el seminario de Guayaquil; dos en el de Cuenca; una en el de Riobamba, y una en el de San Bernardo de Loja (El Nacional -Quito-, núm. 9, 11 de mayo de 1846).

Años después, en 1854, Marcos Espinel, ministro de lo Interior de José María Urbina, defendía la educación como medio para integrar el país: "teniendo [...] el Estado una población compleja o heterogénea, entre la cual se presenta la clase indígena llena de miseria, 
de ignorancia, de abatimiento [...], se hace aquí más imperiosa y absoluta la necesidad de atender con preferencia a la instrucción popular" (cit. en Maiguashca, 1994:379).

La Constitución de 1884 estableció por vez primera el carácter gratuito y obligatorio de la enseñanza primaria, y remitió a los fondos públicos para la financiación de esa enseñanza y de la de artes y oficios (artículo 34): disposiciones todas ellas refrendadas en el texto fundamental de 1897 (artículo 36). Pero la Convención Nacional que aprobó el texto constitucional de 1884 se atrajo la crítica de algunos liberales, como Juan Benigno Vela, que le reprochaban su timidez para extender la instrucción universal a la mujer, como si eso equivaliera a "implantar en el Ecuador doctrinas revolucionarias y anticatólicas" (cit. en Gomezjurado Zevallos, 2010:244).

Celiano Monge Navarrete, amigo de Juan Montalvo y de Juan Benigno Vela, con quienes había fundado en 1878 el periódico La Candela, aunque consciente del lamentable nivel de los maestros y de las insuficiencias escolares de todo orden, no perdía la esperanza -una ilusión ingenua, ciertamente- en la capacidad redentora de la escuela para formar ciudadanos honrados y responsables. Y desde La Pluma, 2 de abril de 1890, un semanario que se proponía contribuir a la mejora de la educación y de incentivo al profesorado, proclamaba su candoroso convencimiento: si todos los niños de una nación recibiesen por seis horas diarias, desde la edad de cinco hasta la de dieciséis años, educación en escuelas servidas por maestros idóneos, se puede asegurar que las noventa y nueve centésimas partes serían buenos ciudadanos, buenos padres y esposos, trabajadores, honrados, patriotas, [y] que ni uno en cada ciento sería desechado como jurado imparcial, ni menos habitaría jamás la cárcel pública (cit. en Gomezjurado Zevallos, 2010:263).

Después de los modestos avances experimentados durante el alfarismo, que no encontraron continuidad, Belisario Quevedo, que discrepaba del presidente Leónidas Plaza Gutiérrez en su apreciación de que el incremento del número de escuelas constituía el remedio para las dolencias nacionales, porque importaba más la calidad que la cantidad, afirmó en línea con las inquietudes de Rocafuerte: "si la escuela no suministra al alma nacional lo que debe suministrar, es inútil hasta cierto punto" (Quevedo, 1981:230).

En fin, Edwing Guerrero, autor de una obrita en que rememora los primeros años del Instituto Mejía de Quito, atribuyó a Plaza Gutiérrez y a sus sucesores la descomposición del sistema educativo ecuatoriano y la ruina de lo avanzado durante el tiempo en que Eloy Alfaro permaneció en el poder: "aquí radica la traición de los que usurparon el poder a nombre del liberalismo; en el abandono, en el olvido, en el desamparo en que mantuvieron a los establecimientos educacionales; crearon las escuelas laicas, pero no las dotaron de lo primordial siquiera" (Guerrero Blum, s.d:102).

Muy recientemente, Juan Valdano ha expresado su pesar por el actual escenario del sistema público de educación, a cuya vista se pregunta: “¿es así como se quiere hacer del Ecuador una patria grande y con una identidad fuerte?” (2007:23).

\section{LAS POLÍTICAS EDUCATIVAS, LA ESCUELA Y LA ENSEÑANZA DE LA HISTORIA 'NACIONAL'}

El convencimiento de la trascendencia de la escuela como medio de mentalización nos compromete a desarrollar en breve plazo una investigación más acuciosa sobre la materia, que trascienda el marco cronológico del siglo XIX, y que sirva de base para la comprensión y la crítica de los modelos vigentes en la actualidad. Un avance de ese compromiso se contiene 
ya en las páginas que siguen, que se centran en el tiempo transcurrido desde la entrada en vigor de la Constitución de 1978, la primera en reconocer el quichua y demás lenguas aborígenes como integrantes de la cultura nacional (artículo $1^{\circ}$ ). La anterior, de 1967, había dado un tímido paso en esa apertura al pluralismo lingüístico, a través de su artículo 38: se propenderá a que los maestros y funcionarios que traten con él [el campesino], conozcan el idioma quichua y otras lenguas vernáculas. En las escuelas establecidas en las zonas de predominante población indígena se usará de ser necesario además del español, el quichua o la lengua aborigen respectiva, para que el educando conciba en su propio idioma la cultura nacional y practique luego el castellano.

La indagación sobre memorias históricas y tradiciones, que es competencia de los profesionales de la historia, ha de ir acompañada y complementada, indudablemente, por políticas educativas que preserven y garanticen los derechos culturales, y posibiliten y faciliten que pueblos y comunidades logren entroncar con sus respectivos pasados, sin las distorsiones manipuladoras que, de modo casi irremediable, han caracterizado a las historias nacionales diseñadas como instrumentos de legitimación de la clase política que en cada momento controla los aparatos del Estado, sea porque así lo han legitimado las urnas, sea porque ha accedido a esa posición a través del uso (o el abuso) de la fuerza. Así lo expresa Torres Castillo: "desde los sectores dominantes, no sólo inventan identidades, comunidades imaginarias a nivel nacional, regional o global, sino también asignan identidades subordinadas, como las de paganos, indios o "minorías"” (2003:199).

Pero, para que esas políticas alcancen éxito se requiere que logren la implicación efectiva del público a que van destinadas; porque, como señala Anne Phillips, "cuando las políticas se diseñan 'para' un público, en lugar de 'con' un público excluido políticamente, es poco probable que tengan en cuenta todas sus necesidades y preocupaciones" (1995:13).

En la medida en que las culturas son realidades en permanente construcción, las políticas educativas impulsadas desde los organismos competentes han de revestir la necesaria flexibilidad para que los textos escolares -en particular, los relacionados con la historia- no incurran en encorsetamientos rígidos ni en clichés anclados en tópicos aceptados de modo acrítico y atemporal, como se aprecia con carácter genérico en los que circulaban en el Ecuador hasta fines de los años ochenta y noventa del pasado siglo (Luna Tamayo, 2001:218-219).

Encuadrado en las directrices de la llamada 'Revolución ciudadana', el objetivo $8^{\circ}$ del Plan Nacional del Buen Vivir 2009-2013, en continuidad con los principios asentados en el artículo 21 de la Constitución ecuatoriana de 2008, define la tradición y la memoria histórica como los caracteres identitarios que aseguran la continuidad de las sociedades en el tiempo, y acata así lo estipulado en la fracción 13 del artículo 57 constitucional, que reconoce los derechos de las comunidades, pueblos y nacionalidades indígenas a "mantener, recuperar, proteger, desarrollar y preservar su patrimonio cultural e histórico como parte indivisible del patrimonio del Ecuador".

Tal apuesta por el reconocimiento de la pluralidad cultural exige superar los prejuicios de quienes rechazan el valor histórico de relatos que no sean conformes con las tipologías historiográficas de Occidente, y niegan en nombre de la ciencia la posibilidad de adentrarse en un pasado que sólo es accesible a través de mitos y de fábulas transmitidos por tradición oral. Una ejemplificación paradigmática de esa mentalidad es un fragmento de Remigio Crespo Toral, donde se niega la posibilidad de una construcción histórica que arranque de un estado ajeno a la 'civilización': "la historia propiamente tal no existe. A poco de rodar el tiempo, los sucesos precedentes se confunden en la niebla del olvido y persisten apenas 
imágenes confusas de mitos y leyendas, de los que nada puede obtenerse en la liquidación de la verdad" (Crespo Toral, s. d: 32).

Al socaire de esos prejuicios, "los pueblos americanos fueron compelidos al culto de una sola tradición", e imperó durante mucho tiempo una visión reduccionista del concepto de nación, desconocedora de que "la principal característica de la modernidad inaugurada por el Descubrimiento de América es la convergencia sobre cada territorio de la mayor diversidad étnica, religiosa y cultural imaginable" (Ospina, 1997:137 y 26). Ese enfoque miope se propagó desde los textos escolares de historia hasta la entrada en vigor de la Constitución de 1998, que proclamó la voluntad del Pueblo del Ecuador, a través de su Asamblea Nacional Constituyente, de "consolidar la unidad de la nación ecuatoriana en el reconocimiento de la diversidad de sus regiones, pueblos, etnias y culturas". Para ejemplificar la visión anterior de la nacionalidad, imperante hasta entonces en líneas generales, nos serviremos del texto de un manual de la Editorial Andina, publicado con anterioridad de quince años a aquel texto constitucional, donde se definía a la nación como

el grupo humano de la misma procedencia étnica, asentado sobre un determinado espacio geográfico, dotado de unidad cultural, religiosa, idiomática y de costumbres, poseedor de un acervo histórico común y de un mismo destino nacional, cuyos miembros se hallan vinculados entre sí por un intenso sentimiento de nacionalidad (García González, s. d.:213214).

\section{EL RECONOCIMIENTO DE LA MULTICULTURALIDAD, PUNTO DE ARRANQUE EN EL APRENDIZAJE DE LA HISTORIA 'NACIONAL'}

Todo lo anterior fundamenta la oportunidad del manual de cívica publicado hace poco más de una década por Enrique Ayala, donde se defiende la idea de que no será posible una reforma educativa a fondo en el Ecuador hasta que se disponga de un pénsum donde, en consonancia con lo prescrito en el artículo 27 de la Constitución vigente, la interculturalidad constituya el punto de arranque; o, más recientemente, del breve texto del mismo autor sobre la interculturalidad, que publicó la Confederación Nacional de Organizaciones Campesinas, Indígenas y Negras (FENOCIN) como parte de los materiales que edita para la capacitación de promotores campesinos (Ayala Mora, 2002:36, y Ayala Mora, 2011:59-61).

El hecho de que la Constitución ecuatoriana de 1998 reconociera el carácter multicultural y multiétnico del Estado abriría un nuevo camino para que un sector importante de la población nacional reivindicara su condición de indígena en el escenario político: “en este contexto [observa Nadège Mazars], el hecho de ser considerados como indígenas -lo que hasta ese momento se vivía como el estigma de un avasallamiento- se vuelve algo valorizador y liberador" (2008:64), aunque susceptible de ser interpretado por algunos como un discurso separatista y tribalizador que, al privilegiar lo indígena, alienta el cultivo de esquemas impermeables de otredad (Handelsman, 2005:29, y Gianni, 2001:23). Por lo demás, el ejercicio de la crítica contribuye de modo positivo a la clarificación y el perfeccionamiento de los programas políticos. No en vano advirtió Montesquieu que el ideal del despotismo consiste en que reine un profundo silencio en todas partes (Montesquieu, 1873:carta 64, 136). A fin de cuentas, como proclamó Enrique Ayala, los indios ecuatorianos han desempeñado un papel fundamental en la historia nacional, porque "no solamente son los originarios pobladores de esta tierra, sino son quienes han tenido mayor vinculación a ella" (Frank, et al., 1992:5). 
Cuando se promulgó la Constitución de 1998 habían pasado ya diez años desde el comienzo de las labores de la Dirección Nacional de Educación Indígena Intercultural Bilingüe (DINEIB), creada para impulsar un programa educativo que respondiera a las demandas de los pueblos indígenas; y doce años desde que en 1986 se formara la CONAIE (Confederación de Nacionalidades Indígenas del Ecuador), primera organización de todos los pueblos indígenas de ámbito nacional, tras la pionera Federación Shuar y organizaciones regionales como la Confederación de Pueblos de la Nacionalidad Kichwa del Ecuador (Ecuador Runacunapac Riccharimui, ECUARUNARI), en la sierra, o la Confederación de Nacionalidades Indígenas de la Amazonía Ecuatoriana (CONFENIAE). Muy posterior fue la puesta en marcha, en 1995, del Movimiento Pachacutik, que se consolidó con el tiempo como el brazo político de la CONAIE (Ayala Mora, 2011:25, 26 e Ibarra Illánez, 1992:95-96 y 99-100). Para entonces se cumplían tres lustros de la celebración del Primer Congreso de las Nacionalidades Indígenas del Ecuador (Sucúa, octubre de 1980).

No cabe duda de que las propuestas y reivindicaciones de esas movilizaciones propiciaron una reinvención de la identidad indígena y contribuyeron a alumbrar un modelo de Estado, al que daría forma la Constitución de 1998, en que la idea de nación plurinacional y multiétnica relevaba a la que tradicionalmente había imperado en los diversos nacionalismos de elites de Iberoamérica, que giraban alrededor del concepto de una nación unitaria y homogénea (Endara Tomaselli, 2003:34-35). Ése es el inspirado enfoque con que un manual de historia de Santillana, editado en Guayaquil en 2000, trata del sentido de las manifestaciones culturales, que cambian de modo constante al transmitirse de generación en generación, como se aprecia en el Ecuador, debido "a la cantidad de pueblos diferentes que han participado en su formación” (Estudios Sociales 4, 2000: 60) [el subrayado es mío].

El texto constitucional de 2008 que, en su capítulo $4^{\circ}$, recoge los derechos de las comunidades, pueblos y nacionalidades indígenas que ya reconocía su predecesor de 1998, los explicita con más detalle, incorpora otros y da un paso más, al asentar como uno de los principios fundamentales del Estado ecuatoriano la plurinacionalidad, y optar por el término 'intercultural' en lugar de 'multicultural'.

La adopción de ese vocablo comporta el compromiso de apertura a la multiplicidad, la heterogeneidad, la pluralidad y al desarrollo de interacciones que reconozcan las asimetrías sociales, económicas, políticas e institucionales, frente a la oposición binaria y la exclusión, el sucedáneo de la tolerancia o el sofisma de la neutralidad (Handelsman, 2005:29 y 58, y Lucas, 2001:80).

Debilitada la soberanía del Estado-Nación a causa de la progresiva expansión de las pautas globalizadoras, y revelada cada vez con más nitidez la incapacidad de aquél para manejar los conflictos de identidades que surgen en su interior y para dar satisfacción a las demandas de reconocimiento de derechos de todas las minorías, surge la interculturalidad como una propuesta sustentada en la ética del reconocimiento, que propugna la construcción de nuestra identidad en relación con el otro (Arista Zerga, 2006:463). La interculturalidad se presenta, en palabras de Fidel Tubino, como "un intento basado en los grandes ideales de la Ilustración por manejar razonablemente el conflicto de las identidades a través del diálogo y la negociación entre las partes" (Arista Zerga, 2006:463).

Si la multiculturalidad constituye más bien un hecho social, la interculturalidad apunta a un modelo de gestión normativa y política de la realidad multicultural y de los conflictos de reconocimiento, en condiciones de igualdad y en un marco democrático que garantice el respeto de las diferencias y del pluralismo: aunque, ciertamente, resulte utópico querer alcanzar la armonía social mediante imperativos legales, también es verdad que la política ha 
de contribuir a adoptar decisiones y procedimientos específicos que marquen reglas del juego acatadas por todas las partes (Lucas, 2001, 63, y Gianni, 2001:45 y 51).

Asentado que la multiculturalidad no constituye un valor por sí misma -no en vano se ha dicho del multiculturalismo que es un "laberinto de equívocos" (Lucas, 2001:61), en parte por su concepción demasiado sustancial de la cultura que desconoce que la noción de dignidad humana es supracultural (Gianni, 2001:41, y Añón Roig, 2001:230)-, queda patente que es susceptible de manipulación de cara a intereses ajenos al respeto de las minorías. Tal ocurre en su versión neoliberal, en la que se presenta como "una manera distinta de entender la diferencia, ubicándola en el espacio del mercado [...]. Los ciudadanos nacionales, entonces, ya no necesitan ser miembros de una sola gran cultura nacional; por el contrario, el mercado ahora tiene espacio para todos, a condición de que sus demandas se diriman en el plano del consumo y no del poder" (Endara Tomaselli, 2003:91).

Se precisa ahora que la legislación ordinaria articule una política educativa coherente con esos postulados y generadora de un contexto de inserción, de modo que los debates en torno a la plurinacionalidad escapen del círculo vicioso que los acecha, para que no oscilen "entre denuncias contundentes contra el movimiento indígena y su supuesto racismo [...], y una estrategia aparentemente conciliadora que pretende incorporar [...] la diversidad cultural 'dentro del aparato estatal al mismo tiempo que la fomenta como un conjunto de particularismos externos al Estado"' (Handelsman, 2005:51, y Lucas, 2001:85-87).

Otro de los manuales de historia del Ecuador de Editorial Santillana, editado en 2010, sostiene con cierta carga de pasión que la interculturalidad debería implicar que el bilingüismo constituyera una aspiración de todos los habitantes del Ecuador, y no sólo de los sectores indígenas: para hablar de bilingüismo tenemos que referirnos exclusivamente al sector indígena. El sector blanco-mestizo no ha comprendido el significado de otro idioma nacional que no sea el español, ni ha aceptado una educación bilingüe basada en otras lenguas nacionales. El hispanoparlante creció en esta tierra sintiéndose dueño y, simplemente, ignoró la existencia de otros pueblos -quichua, tsáchila, shuar, huaorani y awá, entre otros- y sus lenguas (Desafios. Estudios Sociales 6, 2010:88).

Ayala Mora, en cambio, discrepa de la aspiración de imponer el bilingüismo a toda la población, que considera inviable. En su lugar propone incluir en el programa nacional de estudios un curso de cultura que se acerque a la realidad social desde una perspectiva indígena (Frank, et al., 1992:23).

Asentada esa posición de superioridad cultural, pese al mandato constitucional, se sigue por fuerza un estado de cosas que el autor del manual que venimos citando describe así: "el quichua, el shuar y las demás lenguas indígenas existen bajo el español y no con el español ni al lado del español" (Desafíos. Estudios Sociales 6, 2010:88). Tales premisas estorban la viabilidad del derecho que la Constitución reconoce a personas y comunidades a la interactuación de culturas y a la participación "en una sociedad que aprende" (artículo 28).

\section{CONCLUSIONES}

Todo lo expuesto hasta aquí requiere su complemento con un esfuerzo educativo que, como propone Handelsman, despliegue "una especie de pedagogía de las diferencias" (2005:61); y que, de acuerdo con lo que reclama Young, comprometa al Estado en el diseño de "medios institucionalizados para el reconocimiento y la representación de grupos oprimidos" (cit. en Gianni, 2001:38). Para impulsar esas nuevas prácticas culturales resulta 
crucial el sistema educativo. Y, si bien en el Ecuador se ha logrado el meritorio avance de diseñar un sistema especial de educación indígena, intercultural y bilingüe, en conformidad con el artículo 57, fracción 14 de la Constitución, que garantiza a todas las personas el aprendizaje en su propia lengua y ámbito cultural (artículo 29), queda aún la tarea pendiente de concretar los criterios de calidad que estipula el texto fundamental, y lograr que ese programa educativo sea de veras intercultural; pues, como advierte Enrique Ayala, "ahora tiende más bien a ser etnocentrista, con una estructura aislada del conjunto de nuestra educación nacional" (2011:59 y Moya, 2004:77).

El último tramo del siglo XX aportó una revisión en profundidad del imaginario indígena en el Ecuador, por obra de las revueltas de 1990 y 1994, que, junto al levantamiento de enero de 2000, contribuyeron a acelerar la transformación que pondría fin al ideal de una nación blanco-mestiza, y se plantearía la definición de una nueva construcción nacional, que discurre en paralelo a la que se emprendió en Colombia con la convocatoria de la Asamblea Nacional Constituyente, en 1991 (Silva, 1995:11-12, y Castillo Gómez, 2009:161-163 y 194197).

Si bien en enero de 2000 se agruparon muy diversos actores sociales en contra de Jamil Mahuad, no cabe duda de la importante huella indígena en esas jornadas, en las que más de diez mil personas de diversas nacionalidades indígenas se hicieron presentes en la ciudad de Quito, donde se constituyó un Parlamento de los Pueblos del Ecuador (Endara Tomaselli, 2003:61-66).

Ese proceso arrinconó los esfuerzos acometidos con tanto entusiasmo por la generación de 1944, sostenidos en el optimismo voluntarista de la 'nación pequeña' de Benjamín Carrión y en el apoyo dispensado desde la Casa de la Cultura Ecuatoriana que, creada por Carlos Alberto Arroyo del Río con el nombre de Instituto Cultural Ecuatoriano, en noviembre de 1943, fue refundada al año siguiente por José María Velasco Ibarra, con el propósito de reforzar la oficialización de la nación mestiza, "sedimentar el discurso nacional, desarrollar una identidad de pertenencia y reconstruir una narrativa ecuatoriana" (Pagnotta, 2008: pár. 23, y Radcliffe, y Westwood, 1999:114).

Aunque a lo largo de la centuria se llegó también a una recapitulación del pasado español menos marcada por las urgencias, asistimos desde hace años a un cierto revanchismo, comprensible pero quizá desenfocado, ante lo que comportó de agresión la presencia de España en tierras que, con el tiempo, constituirían la República del Ecuador. Aquí, como en tantos otros países de Iberoamérica, los sectores excluidos durante largas centurias tratan de recuperar sus historias para constituirse en sujetos históricos: y, de modo inevitable, en este proceso de reinvención de tradiciones y de identidades se planea un pulso en el que está en juego el control de la memoria social (Torres Carrillo, 2003:198-199).

Por eso la importancia de una continua y sosegada reflexión crítica sobre las representaciones imaginarias -esas ficciones- del pasado que los escritos de historia nos han legado: porque tal vez haya que rectificar automatismos históricos en pos de una reconciliación y de un mutuo reconocimiento que dejen atrás la ontología monista como fundamento de la soberanía y de la política, trasciendan los lugares comunes, superen la dicotomía ideológico-identitaria y venzan los miedos a descubrir la propia identidad (Lucas, 2001:94-95). 


\section{BIBLIOGRAFÍA}

ANDERSON, B. (1993). Comunidades imaginadas: reflexiones sobre el origen y la difusión del nacionalismo. México: Fondo de Cultura Económica

AÑÓN ROIG, M. J. (2001). "La interculturalidad posible: ciudadanía diferenciada y derechos”. En F. J. Lucas Martín (dir.), La multiculturalidad. Madrid: Consejo General del Poder Judicial, pp. 217-270

ARISTA ZERGA, A. (2006). "Ciudadanía multicultural e interculturalidad". Investigaciones Sociales (Lima), año 10, nº 17: 457-472: http://es.scribd.com/doc/103192818/Arista-Zerga-Adriana-CiudadaniaMulticultural-e-Interculturalidad

AYALA MORA, E. (2002). Ecuador: patria de todos. La nación ecuatoriana, unidad en la diversidad. Quito: Universidad Andina Simón Bolívar-Corporación Editora Nacional: http://www.uasb.edu.ec/User Files/File/ecuador\%20patria\%20enrique\%20ayala.pdf

- (2011). Interculturalidad: camino para el Ecuador. Quito: Confederación Nacional de Organizaciones Campesinas, Indígenas y Negras (FENOCIN)

CASTILLO GÓMEZ, L. C. (2009). Etnicidad y nación. El desafío de la diversidad en Colombia. Cali: Universidad del Valle.

CRESPO TORAL, R. (s. d.). “La conciencia nacional”. En R. Crespo Toral, La conciencia nacional y otros estudios sobre Historia. Quito: Biblioteca Grupo Aymesa, pp. 31-66

ENDARA TOMASELLI, L. (2003). “iAy, patria mía!” La nación ecuatoriana en el discurso de la prensa. Quito: Universidad Andina Simón Bolívar-Corporación Editora Nacional y Ediciones AbyaYala.

FRANK, E.; PATIÑO, N. y RODRÍGUEZ, M. (comps.) (1992). Los políticos y los indígenas. Quito: Ediciones Abya-Yala, "Entrevista al Dr. Enrique Ayala Mora", pp. 3-27

GARCÍA GONZÁLEZ, L. (s. d.). Resumen de Geografía, Historia y Cívica. Primer Curso Ciclo Básico. Quito: Editora Andina

GELLNER, E. (2001). Naciones y nacionalismo. Madrid: Alianza Universidad

GIANNI, M. (2001). “¿Cuál podría ser la concepción liberal de ciudadanía diferenciada?”. En F. J. Lucas Martín (dir.). La multiculturalidad. Madrid: Consejo General del Poder Judicial, pp. 13-57

GOMEZJURADO ZEVALLOS, J. (2010). Construyendo nuestra identidad. Estudios Históricos Sociales. Esmeraldas: Casa de la Cultura Ecuatoriana Benjamín Carrión, Núcleo de Esmeraldas

GUERRERO BLUM, E. (s. d.). El Mejía y la educación laica en el Ecuador. Hombres, hechos, ideas. Quito: Editora Eugenio Espejo

HANDELSMAN, M. (2005). Leyendo la globalización desde la mitad del mundo. Identidad y resistencias en el Ecuador. Quito: Editorial El Conejo

HOLGUÍN ARIAS, R. (1994). Estudios Sociales. Primer Curso. Quito: s. e.

IBARRA ILLÁNEZ, A. (1992). Los indígenas y el Estado en el Ecuador. Quito: Ediciones Abya-Yala KÖNIG, H-J. (1994). En el camino hacia la Nación. Nacionalismo en el proceso de formación del Estado y de la Nación de la Nueva Granada, 1750 a 1856. Bogotá: Banco de la República

LUCAS, J. (2001). "La(s) sociedad(es) multicultural(es) y los conflictos políticos y jurídicos". En F. J. Lucas Martín (dir.), La multiculturalidad. Madrid: Consejo General del Poder Judicial, pp. 59-102

LUNA TAMAYO, M. (2001). "Visión comparada de los textos escolares de Historia del Ecuador y de España”. En M. E. Porras, y P. Calvo-Sotelo (coords.), Ecuador-España: Historia y Perspectiva. Estudios. Quito: Embajada de España en el Ecuador-Archivo Histórico del Ministerio de Relaciones Exteriores del Ecuador, pp. 218-221

MAIGUASHCA, J. (1994). "El proceso de integración nacional en el Ecuador: el rol del poder central, 1830-1895”. En J. Maiguashca (ed.), Historia y región en el Ecuador: 1830-1930. Quito: Corporación Editora Nacional-Flacso Sede Ecuador, pp. 355-420

MAZARS, N. (2008). "De la práctica comunitaria indígena a la democracia participativa: experiencias municipales en Ecuador". En VV. AA., Luchas indígenas, trayectorias poscoloniales -Américas y Pacífico-. Bogotá: Editorial Universidad del Rosario, pp. 62-81

MONTESQUIEU, B. (1873). Lettres persanes. Paris: Alphonse Lemerre Éditeur: http://gallica.bnf. fr/ark:/12148/bpt6k208077n/f1 16.image.r=.langES 
MOYA, R. (2004). "Mentalidades, prácticas sociales e interculturalidad en América Latina". En R. Moya, y A. Moya, Derivas de la interculturalidad. Procesos y desafíos en América Latina. Quito: Centro Andino para la Formación de Líderes Sociales (CAFOLIS)-Fundación Andina de Desarrollo y Estudios Sociales (FUNADES), pp. 15-114

NÚÑEZ SÁNCHEZ, J. (2003). El Ecuador en el siglo XIX. Ensayos históricos. Quito: Gobierno de la Provincia de Pichincha-Asociación de Historiadores Latinoamericanos y del Caribe (ADHILAC)-Casa de la Cultura Ecuatoriana

OSPINA, W. (1997). ¿Dónde está la franja amarilla?. Bogotá: Grupo Editorial Norma

OSPINA PERALTA, P. (1996). "Imaginarios nacionalistas: historia y significados nacionales en Ecuador, siglos XIX y XX". Procesos: Revista Ecuatoriana de Historia (Quito), 9: 111-124: http://repositorio.uasb.edu.ec/bitstream/10644/1259/1/RP-09-ES-Ospina.pdf.

PAGNOTTA, C. (2008). "La identidad nacional ecuatoriana entre límites externos e internos". Amérique Latine Histoire et Mémoire. Les Cahiers (Paris), 16: http://alhim.revues. org/3061

PALADINES ESCUDERO, C. (2009). El movimiento ilustrado y la independencia de Quito. Quito: Fondo de Salvamento del Patrimonio Cultural

PAZ, O. (2007). “Crítica a la pirámide”. En El laberinto de la soledad. Madrid: Cátedra, pp. 369-415

PHILLIPS, A. (1995). The Politics of Presence. Oxford: Oxford University Press

QUEVEDO, B. (1981). Ensayos sociológicos, políticos y morales. Quito: Banco Central del EcuadorCorporación Editora Nacional

RADCLIFFE, S. y WESTWOOD, S. (1999). Rehaciendo la Nación. Lugar, identidad y política en América Latina. Quito: Ediciones Abya-Yala: https://repository.unm.edu/bitstream/handle/1928/12683/ Rehaciendo\%201a\%20naci\%C3\%B3n.pdf?sequence $=1$

SILVA, É. (1995). Los mitos de la ecuatorianidad. Ensayo sobre la identidad nacional. Quito: Ediciones Abya-Yala

TODOROV, T. (2011). Nosotros y los otros. Reflexión sobre la diversidad humana. México-Buenos Aires: Siglo Veintiuno Editores

TORRES CARRILLO, A. (2003). "Pasados hegemónicos, memorias colectivas e historias subalternas". En C. Walsh, (ed.), Estudios Culturales Latinoamericanos: retos desde y sobre la región andina. Quito: Universidad Andina Simón Bolívar y Ediciones Abya-Yala, pp. 197-214

URIBE, M. T. (2005). "La elusiva y difícil construcción de la identidad nacional en la Gran Colombia". En F. Colom González, (ed.), Relatos de nación. La construcción de las identidades nacionales en el mundo hispánico, 2 vols. Madrid-Frankfurt: Iberoamericana-Vervuert, vol. I, pp. 225-249

VALDANO, J. (2007). Identidad y formas de lo ecuatoriano. Quito: Eskeletra Editorial VV. AA. (2010). Desafíos. Estudios Sociales 6. Quito: Santillana

VV. AA. (2000). Estudios Sociales 4. Guayaquil: Santillana

VV. AA. (2000). Estudios Sociales 10 E. B. Cuenca: Editorial Don Bosco 
** El presente trabajo fue patrocinado por el Proyecto Prometeo de la Secretaría de Educación Superior, Ciencia, Tecnología e Innovación de la República del Ecuador.

\section{Breve currículo:}

\section{Manuel Ferrer Muñoz}

Doctor en Filosofía y Letras, Sección de Historia, por la Universidad de Navarra (España), y Licenciado en Filosofía y Letras, especialidad de Historias, por la Universidad de Granada (España). Becario Prometeo en el Instituto de Altos Estudios Nacionales (Quito, Ecuador), desde octubre de 2013. Coordinador general del Centro Europeo de Estudios sobre Flujos Migratorios (Gran Canaria, España), desde 2003 hasta 2013. Investigador Titular "C", Tiempo Completo, en el área de Historia del Derecho, en el Instituto de Investigaciones Jurídicas, Universidad Nacional Autónoma de México (UNAM), desde 1994 hasta 2003. Secretario y director de investigación en el Centro de Estudios de Humanidades (Gran Canaria, España), desde 1990 a 1994. 